1 Hocking M, Young DG. Duplications of the alimentary tract. $\mathrm{Br} f$ Surg 1981; 68: 92-6.

2 Stringer MD, Dinwiddie R, Hall CM, Spitz L. Foregut duplication cysts: a diagnostic challenge. $f R$ Soc Med 1993; 86: 174-5

3 Gray SM, Skandalakis VE. The embryological basis for the treatment of congenital defects. In: Gray SM, Skandalakis VE, eds. Embryology for surgeons. 1st Ed. Philadelphia: WB Saunders, 1972: 63-100.

4 Alrakeeah A, Gillis DA, Giacomantonio M, Lau H. Neurenteric cysts - a spectrum. F Pediatr Surg 1988; 23: 752-4.

5 Ildstad ST, Tollerud DJ, Weiss RG, Ryan DP, McGowan MA, Martin MW. Duplications of the alimentary tract. Clinical characteristics, preferred treatment and associated malformations. Ann Surg 1988; 208: 184-9.

6 Dresler CM, Patterson GA, Taylor BR, Moore DJ. Complete foregut duplication. Ann Thorac Surg 1990; 50: 306-8.

7 Burgner DP, Carachi R, Beattie TJ. A thoracic foregut duplication cyst presenting with neonatal respiratory distress and haemoptysis. Thorax 1994; 49: 287-8.

8 Velasco-Siles JM, Paredes E, Escanero A, Alcala H. Spinal cord compression due to cystic duplication of the primitive digestive tract. Childs Nerv Syst 1986; 2: 159 .

9 Goyert GL, Blitz D, Gibson P, et al. Prenatal diagnosis of duplication cyst of the pylorus. Prenat Diag 1991; 11: 483-6.
10 Fitch SJ, Tonkin IL, Tonkin AK. Imaging of foregut duplication cysts. Radiographics 1986; 6: 189-91.

11 Mahoubi S, Finkelstein M, Afonami E. Esophageal duplication in children: a report of three cases evaluated by computed tomography. Pediatr Emerg Care 1985; 1: 90-3.

12 Thurston SE, Lenn NJ. The association of spinal and gastroesophageal anomalies. Case report and review. Clin Pediatr (Phila) 1984; 23: $652-4$.

13 Hemalatha V, Batcup G, Brereton RJ, Spitz L. Intrathoracic foregut cyst (foregut duplication) associated with esophageal atresia. $\mathcal{f}$ Pediatr Surg 1980; 15: 178-80.

14 Dave P, Romeu J, Clary S, Rybak B, Messer J. Endoscopic removal of an obstructing duodenal duplication cyst. Endoscopy 1984; 16: 75-6.

15 Bissler JJ, Klein RL. Alimentary tract duplications in childhood; case and literature review. Clin Pediatr (Phila) 1988; 27: 152-7.

16 Hazebroek FW, Tibboel D, Khick P, Zondervan PE, Molenaar JC. Histopathological investigation of duplications of the alimentary tract. $Z$ Kinderchir 1986; 41: 90-2.

17 Chnang MT, Barba FA, Kaneko M, Tierstein AS. Adenocarcinoma arising in an intrathoracic duplication of foregut origin: a case report and review of the literature. Cancer 1981; 47: 1887-90.

\title{
Orthopaedic management of cerebral palsy
}

Like so many other facets of orthopaedic surgery, the orthopaedic management of the child with cerebral palsy has changed significantly in the last 10 to 20 years. As in many other fields, the technology has advanced rapidly, particularly in the development of the sophisticated assessment of gait in the gait laboratory. As usual with such advances, we have a mass of new data that solves some problems and creates others. Gait laboratories are expensive, labour intensive, and time consuming. They are also limited to children who can walk with or without aids within the confines of the laboratory and can cooperate with those running it. They have added significantly to our knowledge but do not provide an easy answer to the often complex and multidisciplinary problems of the child with cerebral palsy. As a result, the orthopaedic surgeon will find himself working within a multidisciplinary team involving the neuropaediatrician, the physiotherapist, orthotist, and several other professionals involved with the care of these complex patients. At present there are few such laboratories in the UK but it is becoming increasingly difficult for an orthopaedic surgeon to provide satisfactory orthopaedic advice in the walking child without one. A simple well lit walkway with video recording equipment capable of individual frame analysis can provide satisfactory observational analysis of a child's gait (M Pearse et al, European Paediatric Orthopaedic Society, Oporto, April 1994).

In a most important article published in Clinical Orthopaedics and Related Research, Rang and Wright asked the question 'What have 30 years of medical progress done for cerebral palsy?'. ${ }^{1}$ This is a very thought provoking article and should be prescribed reading for all those involved in the management of cerebral palsy. Rang and Wright suggest that the success of medical treatment could be measured in terms of (i) reduction of the incidence and severity of cerebral palsy; (ii) reduction of the patient's disabilities; (iii) reduction of the burden for the family and for society, both in human and in financial terms. Some progress has been made in all these areas but reviewing the patients attending my clinic from week to week, there is no cause for complacency and some justification for thinking in some ways we seem to be going backwards. Modern neonatal care has reduced the mortality of low birthweight premature infants but the incidence of brain damage leading to cerebral palsy in this group does not seem to have changed significantly. ${ }^{2}$

In my own practice, it is the severe end of the spectrum in cerebral palsy, namely, the child with severe spastic quadriplegia or, to use the term popularised by Professor Bleck, the total body involved child, ${ }^{3}$ that has increased most markedly. In the past orthopaedic management, both surgical and orthotic, was rarely considered appropriate for this group. In simple terms, the orthopaedic problems in children with cerebral palsy now break down to those in the ambulant group, for whom gait analysis is becoming more and more important, and the non-ambulant or largely non-ambulant group, in which quality of life as a non-ambulant person is the most important. Nowadays, in order to provide improved seating and mobility in this group, a stable straight spine and stable hips are considered a prerequisite. ${ }^{1}$ The incidence of spinal deformity in this group is high. Control of spinal deformity by bracing is difficult. Surgery is often extensive, time consuming, and not without significant hazard. The natural history of hip displacement in this group suggests that over $50 \%$ will develop progressive displacement and dysplasia and up to $20 \%$ frank dislocation with time. ${ }^{4}$ Scrutton suggests that those children who do not pull to standing by the age of 3 years are at significant risk and radiographs should be taken of their hips once a year to monitor progressive displacement, ${ }^{5}$ which can occur early and be complete by the age of 5 . Abduction splintage is widely used, although its precise role and value have not as yet been clearly evaluated. Early soft tissue surgery performed before displacement, measured by the Reimers migration percentage ${ }^{6}$ as greater than $50 \%$, has been shown to be reasonably successful (K R Wood, J A Fixsen, British Society for Children's Orthopaedic Surgery, 1989). Soft tissue surgery alone, once there is more than $50 \%$ displacement and/or significant acetabular dysplasia, is unlikely to be successful and requires major bony reconstruction of the hip, usually in the form of open reduction, femoral osteotomy, and acetabuloplasty. Like major spinal surgery, this is not without its hazards and is a significant ordeal for the patient and the parents. The alternative of 
allowing the hips to progressively displace and ultimately dislocate is increasingly less acceptable as it would appear that a significant percentage of these hips will become painful. Also, the presence of a dislocated hip will impair the management of both seating and spinal deformity. The important message regarding orthopaedic management in this group is to involve the orthopaedic surgeon early in the management of the child, to monitor the hips and the spine closely from an early age and hope that early intervention, both orthotic and when necessary, surgical, can prevent the major hip and spine deformities that are seen so commonly at present.

Gait analysis has radically altered the orthopaedic surgeon's attitude to the walking diplegic and hemiplegic. With regard to orthoses, particularly ankle foot orthoses, accurate analysis of gait, with and without the orthosis, can reveal much more clearly what it is or is not achieving. Imposing an orthosis that is of no benefit or even deleterious to the gait is just as bad as not making use of one which is beneficial. It is all too easy to fall into the trap of 'doing something' without any proof that what you are doing is truly beneficial. In the past, we were, I think, rightly cautious about surgery. Once done, surgery cannot be undone and the classic approach was to operate at one level only and see the effect before proceeding to further surgery. This became known as the 'birthday operation' syndrome. ${ }^{7}$ Gait analysis has given us the confidence and also the evidence that multilevel surgery is more beneficial and more effective. However, the time necessary for the analysis, the surgery, and the intensive follow up physiotherapy required impose very considerable stresses on the patient and the orthopaedic unit which takes on such surgery. ${ }^{8}$ It seems inevitable that this type of surgery will have to develop in specialised units, who have the time, the multidisciplinary expertise, and the financial support to provide it.

At the end of the day, particularly in a health care environment obsessed by audit and financial problems, we must face up to Rang and Wright's three criteria of success. We must remember that orthopaedic management, surgical or non-surgical, is simply an attempt to adjust at the periphery for a primarily central neurological problem. It can never be curative. A realistic attitude from the patient, parents, therapist, physician, and surgeon is essential if orthopaedic management is to have any hope of success. The human and financial burden cannot be forgotten in a health service, which is finding it increasingly difficult, both in terms of manpower and finance, to satisfy the expectations of those it is trying to treat.

Great Ormond Street Hospital for Children NHS Trust,

J A FIXSEN

London WC1N $3 f H$ and

The Royal Hospital of St Bartholomew,

London

1 Rang M, Wright J. What have 30 years of medical progress done for cerebral palsy? Clin Orthop 1989; 247: 55-60.

2 Bax M. Perinatal care - success or failure? Dev Med Child Neurol 1986; 28: 279.

3 Bleck EE. Orthopaedic management in cerebral palsy. Clinics in developmental medicine No 99/100. Oxford: Blackwell, 1987.

4 Howard CB, McKibbin B, Williams LA, MacKie I. Factors affecting the incidence of hip dislocation in cerebral palsy. $\mathcal{F}$ Bone foint Surg $B r 1985 ; 67$; 530-2.

5 Scrutton D. The management of hips in cerebral palsy. Dev Med Child Neurol 1989; 31: 108-16.

6 Reimers J. The stability of the hip in children. A radiological study of the results of muscle surgery in cerebral palsy. Acta Orthop Scand 1980; 184: $1-97$.

7 Rang M, Silver R, De La Garza J. Cerebral palsy. Lovell WW, Winter RB, eds. Pediatric orthopedics. 2nd Ed. Vol 1. Philadelphia: JB Lippincott, 1986. 8 Nene AV, Evans GA, Patrick JM. Simultaneous multiple operations for spastic diplegia. $\mathcal{f}$ Bone foint Surg Br 1993; 75: 488-94. 